\title{
Wireless Sensor Network (WSN) application for Monitoring the River Water Level
}

\author{
Imam Abdul and Rozaq ${ }^{1}$, Erwin Satriyanto ${ }^{2}$ \\ \{imam.rozaq@umk.ac.id ${ }^{1}$,erwinsatriyanto@gmail.com $\left.{ }^{2}\right\}$ \\ Departement of Electrical Engineering, Universitas Muria Kudus, Gondangmanis PO.BOX 53, Telp: \\ +62291-438229/ Fax: +62291-437198 12
}

\begin{abstract}
The increased risk of flooding in terms of magnitude and frequency in urban areas encourages people to act for flood mitigation measures. The method used is research and development. The stages of the research stage came from the simple WSN used and modifications in this study were (1) the assembly of ultrasonic sensor components for characterization and calibration of the ultrasonic sensor (2) analysing the accuracy of the ultrasonic sensor and if the water level in STANDBY3, STANDBY2, and STANDBY1 conditions would provide notification in the form of SMS. The results of the research that has been carried out concluded that the static testing of PING ultrasonic sensors has an average error of $2.167 \%$ and an accuracy value of $97.833 \%$. testing of ultrasonic sensors ping dynamically has an average error of $1.97 \%$ with an accuracy of $98.03 \%$. Static notification testing reaches $100 \%$ success rate.
\end{abstract}

Keywords: WSN, monitoring, river water level, ultrasonic ping.

\section{Introduction}

Increasing the probability of flood risk in terms of magnitude and frequency in urban areas encourages people to act for flood mitigation measures, one of which is by monitoring river water levels so that they can anticipate before a flood occurs, then warn residents so that residents can prepare themselves in overcoming flooding so they can be minimizing flood losses, either fatalities or losses. [2] [3]

Indonesia is a country that has high rainfall. The rainy season usually lasts for 6 months from October to March. Flood disasters still occur continuously in Indonesia. The Kudus City is one of the cities that is often hit by floods. It is undeniable that flood disasters also occur because there are still many people who litter. The frequent occurrence of floods is one of the factors associated with this research. The lack of information obtained by the community at the time of the flood and ultimately the community cannot prepare themselves. In emergency information delivery, a monitoring and warning system is needed for the public. The monitoring system must be accessible quickly, easily, anywhere and anytime. As well as the need for an early warning that can inform the public that the increase in water levels reaches a dangerous level for the community.

According to Sulistyowati R. In A River Water Level Monitoring System Using AndroidBased Wireless Sensor Networks for a Early Warning System Flood says that the test results on the performance of ultrasonic sensors show an average error rate of $1.121 \%$ and an error rate on the speed of change in the water level of $1 \mathrm{~cm}$. Sending SMS on smartphones gets the ICCSET 2018, October 24-25, Kudus, Indonesia Copyright (C) 2018 EAI DOI 10.4108/eai.24-10-2018.2280506 
average delivery time of $5,414 \mathrm{~s}$, there is no data backup while in our study there is a data check that is using the Tingspeak website that can be accessed using a Personal Computer or using a smartphone. [6]

Based on these problems and the latest developments in low-powered small sensor technology, sensor nodes are widely used in a variety of applications in environmental monitoring so that the need for a water level monitoring system in real time and can provide notifications in the form of SMS when the water reaches STANDBY3, STANDBY2, and STANDBY1. This monitoring tool is connected with internet technology using Thingspeak cloud computing that can be monitored from anywhere and anytime. [1]

\section{Research Method}

The research method used in this study is Research and Development which is using a simple Wireless Sensor Network (WSN) which can be seen in Figure 1. The next stage of the research comes from the simple WSN used and modifications in this study are (1) assembly of ultrasonic sensor components for characterization and calibration of the ultrasonic sensor (2) analysing the accuracy of the ultrasonic sensor and if the water level in STANDBY3, STANDBY2, and STANDBY1 conditions will provide an SMS notification. For more details, see Figure 2.

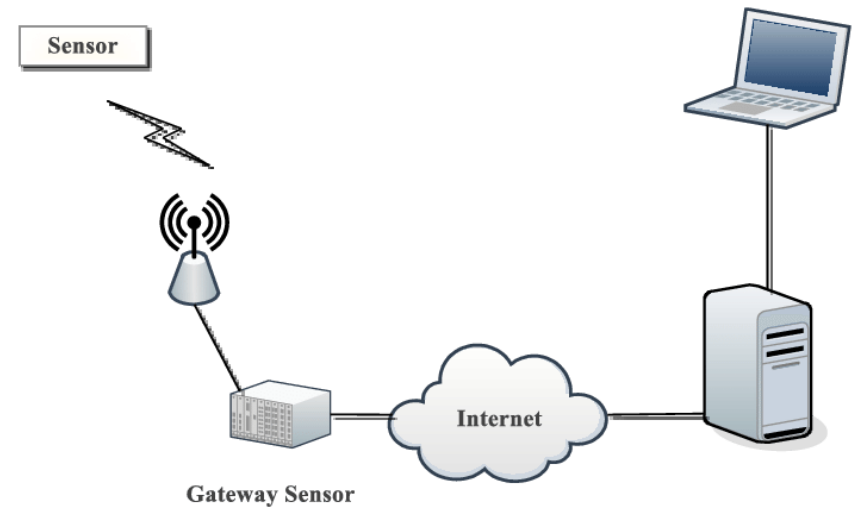

Fig. 1. A simple WSN architecture. [5].

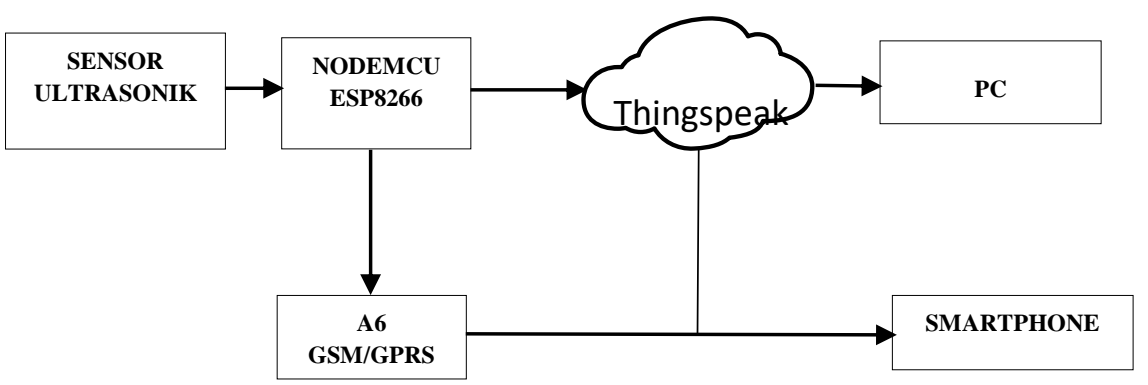

Fig. 2. WSN for water level monitoring systems. 


\subsection{Component Assembly}

In making a monitoring system the selection of hardware components that are used is very important to note so that it takes several components that must be assembled which can be seen in Figure 3.

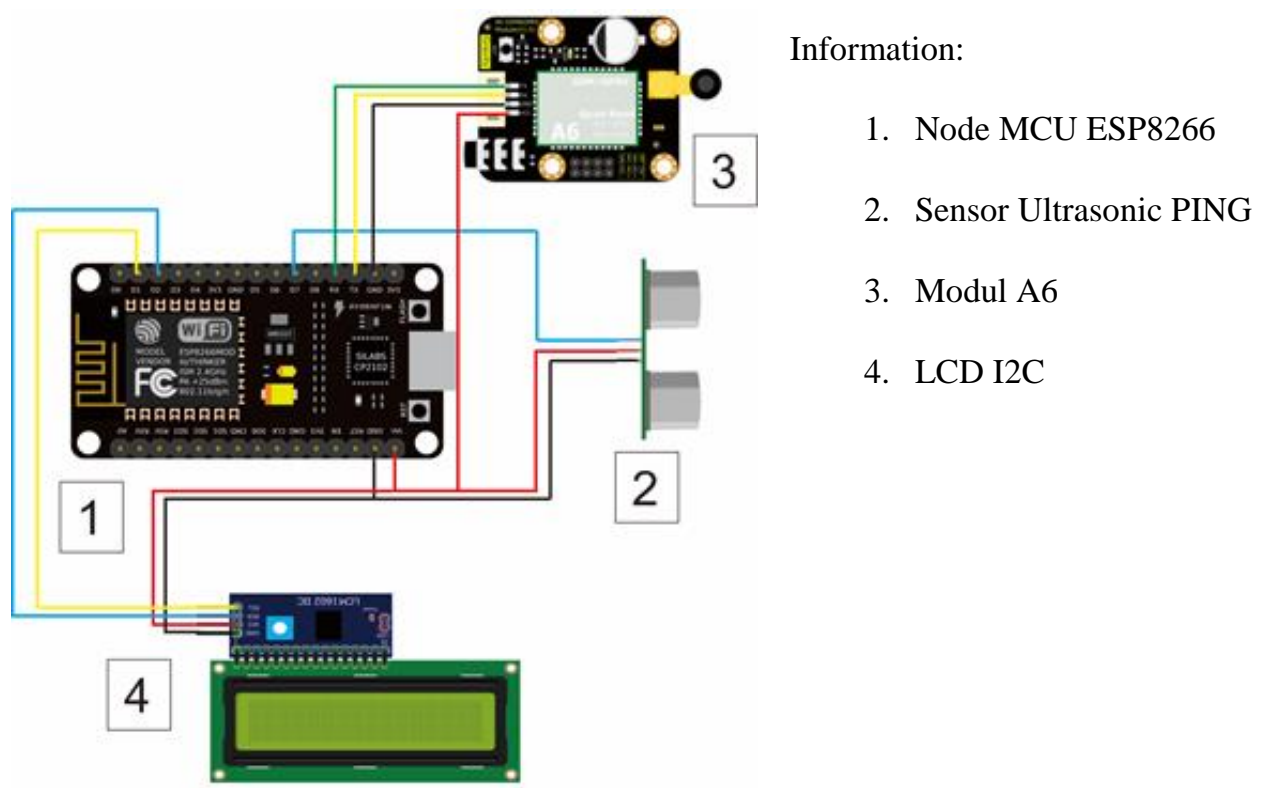

Fig. 3. Wiring Scheme for Monitoring the river water level system.

To make a monitoring system, the sensor needs to be equated with a measuring instrument so that the sensor can be trusted in reading a statement if it is not the same then the level of error and accuracy is needed. To get the error rate and accuracy you can use this formula[4]

$$
\text { Error } \%=\frac{x-y}{x} x 100 \%
$$

(1)

$$
\text { Accuracy }=100 \%-\text { Error } \%
$$

(2)

Information :

$\mathrm{x}=$ sensor used

$\mathrm{y}=$ measuring instrument used 


\section{Results and Discussion}

\subsection{Static Ultrasonic Sensor PING Testing Results}

The first test conducted in this research is not only one test but by doing 2 tests to get the maximum data with the same water level between test 1 and test 2 , the surface starting from $3 \mathrm{~cm}$ to $30 \mathrm{~cm}$.

Table 1. Static ultrasonic sensor Ping testing.

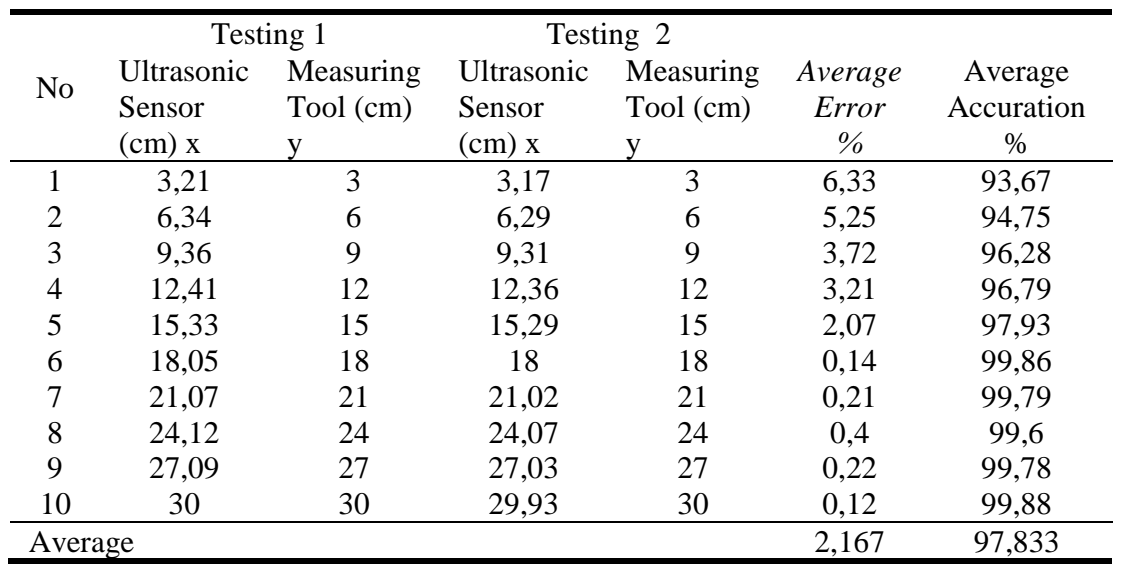

From the results of data calculations on the ultrasonic sensor ping static test, the error value was $2.167 \%$ and the accuracy value was $97.833 \%$.

\subsection{Dynamic Testing Results of PING Ultrasonic Sensors}

This test is carried out to determine the response of the sensor changes in water gradually by filling the water continuously from the water level from the surface of $37 \mathrm{~cm}$ to $2 \mathrm{~cm}$ in real time.

Table 2. Dynamic Testing Results of PING Ultrasonic Sensors.

\begin{tabular}{cccccc}
\hline NO & Time & $\begin{array}{c}\text { Readings on } \\
\text { Thingspeak.com }(\mathrm{cm})\end{array}$ & $\begin{array}{c}\text { Measuring } \\
\text { Tool }(\mathrm{cm})\end{array}$ & $\begin{array}{c}\text { Average } \\
\text { Error } \%\end{array}$ & $\begin{array}{c}\text { Average } \\
\text { Accuration } \%\end{array}$ \\
\hline 1 & $14: 22: 23$ & 37,14 & 37,1 & 0,11 & 99,89 \\
2 & $14: 22: 40$ & 35,71 & 35,7 & 0,03 & 99,97 \\
3 & $14: 22: 57$ & 34,24 & 34,2 & 0,12 & 99,88 \\
4 & $14: 23: 14$ & 32,62 & 32,6 & 0,06 & 99,94 \\
5 & $14: 23: 31$ & 31,67 & 31,6 & 0,22 & 99,78 \\
6 & $14: 23: 48$ & 30,95 & 30,5 & 1,48 & 98,52 \\
7 & $14: 24: 05$ & 28,43 & 28,4 & 0,11 & 99,89 \\
8 & $14: 24: 22$ & 26,67 & 26,6 & 0,26 & 99,74 \\
9 & $14: 24: 39$ & 25,65 & 25,6 & 0,2 & 99,8 \\
10 & $14: 25: 00$ & 23,88 & 23,8 & 0,34 & 99,66 \\
11 & $14: 25: 22$ & 22,15 & 22,1 & 0,23 & 99,77 \\
12 & $14: 25: 43$ & 20,71 & 20,5 & 1,02 & 98,98 \\
\hline
\end{tabular}




\begin{tabular}{cccccc}
\hline NO & Time & $\begin{array}{c}\text { Readings on } \\
\text { Thingspeak.com }(\mathrm{cm})\end{array}$ & $\begin{array}{c}\text { Measuring } \\
\text { Tool }(\mathrm{cm})\end{array}$ & $\begin{array}{c}\text { Average } \\
\text { Error } \%\end{array}$ & $\begin{array}{c}\text { Average } \\
\text { Accuration } \%\end{array}$ \\
\hline 13 & $14: 26: 07$ & 18,45 & 18,4 & 0,27 & 99,73 \\
14 & $14: 26: 31$ & 17,14 & 16,9 & 1,42 & 98,58 \\
15 & $14: 26: 54$ & 15,22 & 15 & 1,47 & 98,53 \\
16 & $14: 27: 17$ & 13,43 & 13,2 & 1,74 & 98,26 \\
17 & $14: 27: 40$ & 11,59 & 11,3 & 2,57 & 97,43 \\
18 & $14: 28: 03$ & 9,83 & 9,5 & 3,47 & 96,53 \\
19 & $14: 28: 26$ & 7,83 & 7,5 & 4,4 & 95,6 \\
20 & $14: 28: 49$ & 6,4 & 6 & 6,67 & 93,33 \\
21 & $14: 29: 13$ & 4,15 & 4 & 3,75 & 96,25 \\
22 & $14: 29: 36$ & 2,38 & 2,1 & 13,33 & 86,67 \\
\hline \multicolumn{2}{l}{ Average } & & & 1,97 & 98,03 \\
\hline
\end{tabular}

From the calculation of the data on the dynamic testing of the PING ultrasonic sensor, the error value is $1.97 \%$ and the Accuracy value is $98.03 \%$.

\subsection{Dynamic Testing with SMS Notification}

Dynamic testing with this notification is carried out with water conditions continuously increasing in real time with water conditions ranging from STANDBY 3 to STANDBY 1.

Table 3. Dynamic Testing with SMS Notification.

\begin{tabular}{cccccc}
\hline NO & Time & $\begin{array}{c}\text { Readings on } \\
\text { Thingspeak.com }(\mathrm{cm})\end{array}$ & $\begin{array}{c}\text { Threshold } \\
(\mathrm{cm})\end{array}$ & $\begin{array}{c}\text { Notification } \\
(\text { yes/ no })\end{array}$ & Condition \\
\hline 1 & $12: 34: 52$ & 22,57 & $<25$ & yes & STANDBY 3 \\
2 & $12: 35: 13$ & 20,67 & $<25$ & yes & STANDBY 3 \\
3 & $12: 35: 35$ & 18,91 & $<20$ & yes & STANDBY 2 \\
4 & $12: 35: 56$ & 17,45 & $<20$ & yes & STANDBY 2 \\
5 & $12: 36: 18$ & 15 & $<20$ & yes & STANDBY 2 \\
6 & $12: 36: 39$ & 13,28 & $<20$ & yes & STANDBY 2 \\
7 & $12: 37: 03$ & 11,28 & $<20$ & yes & STANDBY 2 \\
8 & $12: 37: 22$ & 9,5 & $<10$ & yes & STANDBY 1 \\
9 & $12: 37: 44$ & 7,81 & $<10$ & yes & STANDBY 1 \\
10 & $12: 38: 06$ & 5,88 & $<10$ & yes & STANDBY 1 \\
11 & $12: 38: 27$ & 3,65 & $<10$ & yes & STANDBY 1 \\
12 & $12: 38: 48$ & 1,9 & $<10$ & yes & STANDBY 1 \\
\hline
\end{tabular}


From the table above can be that there are two conditions of STANDBY 3, the notification of which is sent, then there are five conditions of STANDBY 2, the five conditions are also sent, in addition there are five conditions for STANDBY 1, the fifth condition of being cancelled is sent either to the telephone cellular that has been set in delivery SMS notification. By looking at the data that has been tested it can be notified that testing the Wireless Sensor Network application to monitor river water level with SMS notification goes well with indicators of all conditions, be it on Condition 1, condition STANDBY 2, and Condition STANDBY 3 all sent in addition using the table above, we show the reading on tingspeak.com

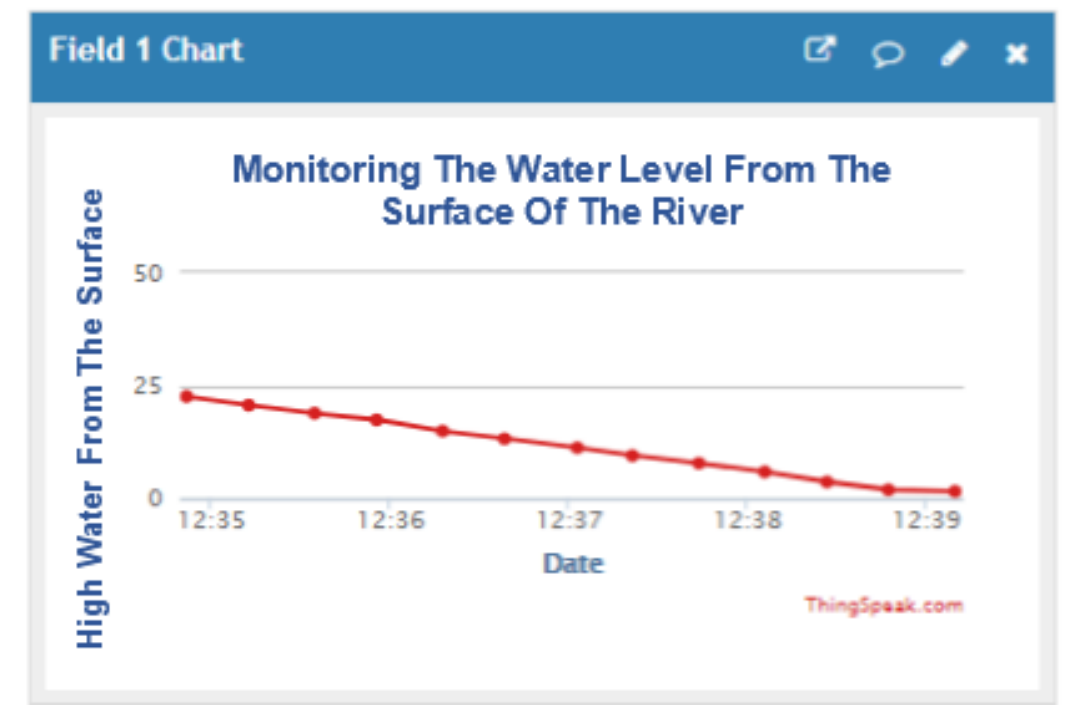

Fig. 4. Display readings of water levels using the ThingsPeak.com website.

\section{Conclusion}

Based on the results of the research that has been carried out, some conclusions can be drawn as follows:

a) Test results Static Ultrasonic Ping sensors have an average error of 1 of $2.16 \%$ and an accuracy value of $97.83 \%$. and the Dynamic Ultrasonic sensor Ping testing results have an average error of $1.97 \%$ with an accuracy of $98.03 \%$.

b) Design feedback information on water conditions starting from STANDBY 3 if the water level from the surface is $<25 \mathrm{~cm}$, STANDBY 2 if the water level from the surface is $<20 \mathrm{~cm}$, and STANDBY1 if the water level from the surface is $<10 \mathrm{~cm}$.

c) Static test results and Dynamic testing SMS notifications have a success rate of $100 \%$

\section{References}

[1] Saidu Idris and Lal Merving Dharmasiri: Flood risk inevitability and flood risk management in urban areas: A review, 1Department of Geography, Sri Lanka.(2015)

[2] Indira Priyadarshinee, Kabita Sahoo, Chandrakant Mallick: A Model for Flood Prediction and 
Prevention using Wireless Sensor Network. International Conference on Emergent Trends in Computing and Communication (2015

[3] Mukhdeep Singh Manshahia : Wireless Sensor Networks: A Survey. International Journal of Scientific \& Engineering Research, Volume 7, Issue 4, (2016)

[4] Jones, L. D: Electronic Instruments and Measurements'. (1991)

[5] Wazir, Jaffer \& Barukab, Omar \& Omran Almagrabi, Alaa \& Afzal Khan, Sher.: Minimizing Denial of Service Attack for Multiple Base Stations in Wireless Sensor Network VFAST Transactions on Software Engineering (2016)

[6] I Sulistyowati R., Sujono H.A., Musthofa A.K.: A River Water Level Monitoring System Using Android-Based Wireless Sensor Networks for a Flood Early Warning System. : Proceedings of Second International Conference on Electrical Systems, Technology and Information 2015 (2015). 